\title{
Sodium and health: New proposal of distribution for major meals*
}

\author{
Renata Puppin Zandonadi, Raquel B. A. Botelho, Verônica C. Ginani, \\ Rita de Cássia C. A. Akutsu, Karin Eleonora de Oliveira Savio, Wilma M. C. Araújo
}

Research Group in Nutritional and Nourishment Quality, Department of Nutrition, University of Brasilia, Brasilia, Brazil; raquelbotelho@terra.com

Received 28 October 2013; revised 6 December 2013; accepted 20 December 2013

Copyright (C) 2014 Renata Puppin Zandonadi et al. This is an open access article distributed under the Creative Commons Attribution License, which permits unrestricted use, distribution, and reproduction in any medium, provided the original work is properly cited. In accordance of the Creative Commons Attribution License all Copyrights (C) 2014 are reserved for SCIRP and the owner of the intellectual property Renata Puppin Zandonadi et al. All Copyright @ 2014 are guarded by law and by SCIRP as a guardian.

\section{ABSTRACT}

Sodium ingestion in regular diet exceeds individuals' physiological needs, and it is etiologically related to various diseases. Studies estimate that the worldwide average individual intake of sodium reaches almost double the maximum limit of ingestion for the day only in the main meals: lunch and dinner. Culturally, sodium is highly used in meals to enhance the flavor of preparations. Then, the purposes of this research are to evaluate sodium use in meals prepared in Popular Brazilian Restaurants and to suggest the distribution of sodium for each kind of preparation of major meals. This is an exploratory cross-sectional research based on direct documentation subdivided in six steps: determination of samples of foodservices and menus; development of the technical preparation files offered in the menus; determination of the weight of average portions offered; determination of the average amount of sodium in the portions offered; estimation of sodium distribution regarding two parameters; and determination of the sodium distribution among preparations of major meals by the two proposed parameters. For results' analysis, portions were calculated as well as the mean contribution of the preparation in the plate weight in percentage and the mean sodium contribution. Standard deviation is also presented. We verified through the study the possibility of using the distribution of sodium by

\footnotetext{
*Funding/Support: The research received funding from the Brazilian government though the "Ministério do Desenvolvimento Social e Combate à Fome”. The research received financial support for translation by the University of Brasília (Edital DPP/UnB 05/2012).

The authors declare that they have no conflict of interests.
}

two parameters: the first one considers the ratio of components' weight in the menu in relation to the total weight of the meal; the second one considers the distribution of sodium in preparations in relation to the total amount of sodium in the meal. We expect the results of this research to improve menu planning in restaurants as to fulfill the actual clients' needs in order to prevent diseases.

\section{KEYWORDS}

Sodium; Menu; Foodservice; Parameter; Meal; Lunch

\section{INTRODUCTION}

In general, sodium ingestion in regular diet exceeds the physiological needs of individuals and is etiologically related to global epidemics of hypertension, cardiovascular diseases, gastric cancer, osteoporosis and obesity [1-5].

Studies estimate that the worldwide average individual intake of sodium reaches almost double the maximum limit of ingestion for the day only in the main meals: lunch and dinner, corresponding to about $4000 \mathrm{mg}$ [6]. In Brazil, recent research reveals an average daily consumption of sodium higher than $4500 \mathrm{mg}$ [7], while the reference for maximum sodium consumption in the Country is $2000 \mathrm{mg}$ per day [8]. The Institute of Medicine, Food and Nutrition Board (IOM) [9] names a tolerable maximum ingestion of $2300 \mathrm{mg}$ of sodium per day.

In accordance to Spinelli and Koga [10], the population's consumption of salt is considered arising from three main sources: $75 \%$ from foods prepared for the main meals, $10 \%$ from intrinsic sodium (naturally pre- 
sent in food) and $15 \%$ from the salt added at the moment of the consumption, highlighting the importance of the control in the preparation of main meals. Culturally for many centuries, sodium is used not only to enhance flavor but also to preserve food. In Brazil, it is very common to produce dry meat using high amounts of sodium as well as canned vegetables.

Researches reveal that meals produced in foodservices have high sodium content, showing in only one meal the daily maximum [11-13]. Due to the sodium property of enhancing food flavor, there is an excessive use of salt in preparations [14], exposing consumers to the risk of high sodium intake.

Considering that main meals (lunch or dinner) contemplate greater energy and nutrients' ingestion (about $40 \%$ of daily recommendation), and that lunch is one of the meals eaten out of home [15], the purposes of this research are to evaluate sodium use in meals prepared in Popular Brazilian Restaurants and to suggest the distribution of sodium for each kind of preparation of major meals.

\section{MATERIAL AND METHODS}

This is an exploratory cross-sectional research based on direct documentation subdivided in six steps: 1) determination of samples of foodservices and menus; 2) development of the technical preparation files (TPFs) [16] offered in the menus; 3) determination of the weight of average offered portions; 4) determination of the average amount of sodium in the offered portions; 5) estimation of sodium distribution regarding two parameters. The first one considers the ratio of components' weight in the menu in relation to the total weight of the meal. The second one considers the distribution of sodium in preparations in relation to the total amount of sodium in the meal; 6) determination of the sodium distribution among preparations of major meals by the two proposed parameters. The study was approved by the Committee of Ethics and Research of the University of Brasilia (Protocol No. 037/10).

In order to select the foodservices, the following criteria of inclusion were used: 1) to be a foodservice that offers popular menus for the Brazilian government program; 2) signature of the Institution Awareness Terms by the Responsible of the foodservice; 3 ) functioning during lunch time; 4) serving more than 500 meals per day. Based on the inclusion criteria, 65 foodservices were considered to be able to take part in the project. As of the population $(\mathrm{N})$ found, the sampling plan was calculated, by considering one sampling mistake (e) of a daily meal and a significance level of $(\alpha) 5 \%$ [17]. A simple random sample was estimated using the procedure selection survey of the program SAS 9.1.3. The final sample consisted of 37 foodservices, following the stratification criteria per each one of the five Brazilian geographical regions.

The menus offered in the services were popular. That is, they present low cost as well as low complexity upon preparation [18] and they are consumed by a majority of the population. For the nutritional evaluation of preparations, TPFs were developed for all components in the researched menus: main dish (protein preparation, from animal origin, usually determining the selection of other items); garnish (accompanies the main dish, possible main ingredient: vegetables, pastry, tubers, flours); accompaniments (items culturally identified by the target population and usually offered. Eg in Brazil: rice, beans and bread); appetizer (cold and/or hot preparations. Cold appetizers may be raw and cooked vegetables; hot appetizers are soups and consommé) [18].

During the elaboration of the preparations, the TPF data was recorded in accordance with Akutsu et al. [16]. This tool suggests that all ingredients used in the preparation are listed, gross and net weight, respective correction factors, preparation yield and cooking factor obtained for each ingredient. The preparation manner must be described in detail, including cooking method, type of equipment and utensils required for the preparation.

From TPFs, the calculation of the nutritional value was done using the DietWin Professional version $2008^{\circledR}$ software, considering information available in the Brazilian Table of Food Composition [19]. In case this information was not available, it was supplemented by nutritional publications, researches and information shown in food product labels. In total, 595 TPFs were analyzed, distributed among the components in the menus. All the preparations were weighed, in order to evaluate the yield.

The weighing in order to define portions in each foodservice was carried out in the distribution counters, according to the standardized arrangement of preparations by employees responsible for serving the portions of food. An electronical scale with $2 \mathrm{Kg}$ maximum capacity and accuracy of $0.01 \mathrm{~g}$ was used (Marte ${ }^{\circledR}$ ). From the average portions served to the clients in each unit, the average portions were calculated for each preparation in the 37 Foodservices, thus we could estimate the contribution in percentage of each preparation served on the client's plate before consumption. That is, for each item in the menu, the average portion was calculated and how much in percentage this item contributed to the full meal of the client.

Considering the data obtained, the average weight of the offered dishes, the average weight of portions of each preparation group and the average amount of sodium per preparation group were determined. Thus, two parameters for analyses were defined in order to determine the sodium content in planning menus: the first one considers the sodium distribution from the ratio of components' 
weight in the menu in relation to the total weight of the meal and the second one considers the sodium distribution in preparations regarding the total amount of sodium in the meal checked through TPFs, that is, distribution of sodium in greater proportions for the preparations that show higher sodium content.

In order to determine the sodium offer, the IOM's recommendation was used as a reference [9] (2300 mg of sodium per day), and lunch accounting for $40 \%$ of the daily ingestion. Thus, the maximum sodium content in lunch is $920 \mathrm{mg}$.

In order to analyze the menus, all preparations were organized per kind of food or per cooking technique used in order to discuss the use of salt (sodium chloride). Thus, for main course, they were grouped in bovine meats, pork meat, chicken, charcuterie or viscera. The garnishes were: pastry, tubers, toasted manioc flour/mash, polenta/corn mash/crushed rice, cooked vegetables. The appetizers were grouped and divided in raw vegetables, cooked vegetables, food in cans and soups. For the accompaniment 1 plain white rice or rice added to other ingredients and for accompaniment 2, plain beans or beans added to other ingredients.

\section{STATISTICAL METHODS}

This is one exploratory cross-sectional research based on direct documentation. Sixty five foodservices were considered able to take part in the project. The sampling plan was calculated, by considering one sampling mistake (e) of a daily meal and a significance level of $(\alpha) 5 \%$. A simple random sample was estimated through the procedure survey select of the program SAS 9.1.3. The final obtained sample was 37 foodservices.

For results analysis, average of the portions was calculated as well as the mean contribution of the preparation in the plate weight in percentage and the mean sodium contribution. Standard deviation is also presented. The frequency in percentage of the preparations in the meals was calculated and demonstrated in table. Since the results are recommendations of sodium use in food preparation, there was no need for further statistical treatment of data.

\section{RESULTS}

The data shown in Table $\mathbf{1}$ indicates the percent distribution of the component items in the menu, as well as the average percentage contribution of average sodium offered in each one of the preparations.

Data presented in Table $\mathbf{1}$ is the first step to analyze the composition of the populations 'plate and the amount of sodium offered by the foodservices. The majority of the meal is composed of rice, beans and meat $(74.02 \%$ of the plate's weight). However, these three components offer $82.19 \%$ of the sodium of the meal. Beans represent $22.7 \%$ of the plate's weight, but they only contribute with $18.76 \%$ of the sodium. Rice presents higher portions and higher sodium content being a dish that needs to be improved.

As for the frequency of the offered preparations, we concluded that raw vegetables and chicken meat dishes are items most available, while soups and canned food are preparations with lower offer (Table 2). Chicken is common in Brazil since it is cheaper to produce. The majority of the salads is green leafy vegetables (86.16\%) that are easier to produce in a large scale. Cooked vegetables were more used as garnish and they help to nutritionally adequate diet. White rice and Plain beans were most frequent, $91.1 \%$ and $68.8 \%$ respectively.

Considering the data obtained, the amount of sodium that could be added to preparations was established to compose the meal (Table 3). A proposal was done considering the portion contribution of each preparation on the plate and another proposal considering the sodium contribution of each preparation. The professional responsible for the foodservice may choose the criterion which fits their production reality.

\section{DISCUSSION}

The present literature discusses sodium intake by

Table 1. Average portion and sodium content in the components in the menu and distribution percentage within the meal.

\begin{tabular}{ccccc}
\hline Component of the menu & $\begin{array}{c}\text { Meal average } \\
\text { portion } \pm \mathbf{D P}(\mathbf{g})\end{array}$ & $\begin{array}{c}\text { Contribution of the } \\
\text { Preparation in dish } \\
\text { weight } \pm \mathbf{D P} \text { (\%) }\end{array}$ & $\begin{array}{c}\text { Average Sodium } \\
\text { defined by portion } \\
\pm \mathbf{D P}(\mathbf{m g})\end{array}$ & $\begin{array}{c}\text { Sodium contribution in the } \\
\text { preparation in relation to the total } \\
\text { amount of sodium offered } \pm \mathbf{D P} \text { (\%) }\end{array}$ \\
\hline Main course & $123.17 \pm 31.54$ & $21.50 \pm 5.87$ & $765.36 \pm 416.46$ \\
Garnish & $86.43 \pm 29.24$ & $14.74 \pm 4.80$ & $311.43 \pm 211.41$ \\
Accompaniment $\mathbf{1}$ & $174.60 \pm 43.80$ & $29.82 \pm 6.42$ & $764.90 \pm 341.01$ \\
Accompaniment $\mathbf{2}$ & $133.20 \pm 31.46$ & $22.70 \pm 5.41$ & $416.02 \pm 163.12$ \\
Appetizer & $71.56 \pm 47.50$ & $11.24 \pm 6.18$ & $114.11 \pm 135.33$ \\
Total & $587.80 \pm 87.40$ & 100 & $2368.10 \pm 708.96$ \\
\hline
\end{tabular}


Table 2. Frequency of occurrence of items that compound the evaluated menus.

\begin{tabular}{|c|c|c|c|}
\hline Preparations & Offer Percentage & Preparations & Offer Percentage \\
\hline Appetizers & \multicolumn{3}{|c|}{ Main course } \\
\hline Raw green leafy vegetables & 86.60 & Bovine meat & 37.60 \\
\hline Cooked vegetables served cold & 8.00 & Pork meat & 6.30 \\
\hline Canned food & 1.40 & Charcuterie & 9.80 \\
\hline Soups & 0.60 & Chicken meat & 41.80 \\
\hline Without offer & 3.40 & Viscera & 4.50 \\
\hline Garnish & \multicolumn{3}{|c|}{ Accompaniment 1} \\
\hline Pastry & 21.40 & Rice & 91.10 \\
\hline Tubers & 17.00 & Rice with other ingredients & 7.10 \\
\hline Toasted manioc flour/mash & 17.00 & Other & 1.80 \\
\hline Polenta/corn mash/crushed rice & 6.30 & & \\
\hline Cooked vegetables served hot & 35.70 & & \\
\hline Without offer & 2.70 & & \\
\hline \multicolumn{4}{|l|}{ Accompaniment 2} \\
\hline Beans & 68.80 & & \\
\hline Beans with other ingredients (meat or vegetables) & 23.10 & & \\
\hline Other & 8.10 & & \\
\hline
\end{tabular}

Table 3. Determination of the amount of sodium per average portion for each item in the lunch menu regarding the average distribution of weight and average distribution of sodium.

\begin{tabular}{ccc}
\hline & Distribution per weight ration of preparations & Distribution per sodium ratio in preparations \\
\hline Main course & Sodium content $(\mathbf{m g})$ & Sodium content (mg) \\
Garnish & 193.20 & 299.00 \\
Accompaniment 1 & 138.00 & 124.20 \\
Accompaniment 2 & 285.20 & 303.60 \\
Appetizer & 220.80 & 170.20 \\
Total & 82.90 & 23.00 \\
\hline
\end{tabular}

worldwide population and the contribution of the industrialized products for this consumption [20]. However, they lack studies that guide restaurants in strategies for the sodium reduction and, thus, lower consumption of this mineral for clients. The proposal of sodium distribution in preparations in a menu is one way of guiding population on the proper consumption of this nutrient, as alleged by IOM [9] and the Worldwide Health Organization (WHO). It is also a strategy for restaurants to choose optimal preparations and be concerned in producing meals appropriate for clients.

In order to achieve that, the food offer in restaurants during lunch throughout the Brazilian territory was evaluated and we found that the average weight of dishes served to clients was $587.80 \mathrm{~g}$. The sodium distribution percentage for preparations of this meal was calculated given the weight and also in relation to the total sodium in the meal (2368.10 mg) for definition of the parameters of sodium distribution.

Remarkably the sodium amount offered was higher (257.4\%) than the maximum limit of ingestion for this meal. The new distribution proposal is based on the maximum sodium amount recommended for lunch (920 mg) [9]. The reduction of approximately $61 \%$ of sodium 
used for this meal is required. It is known that the sodium reduction in isolated manner results in food rejection by consumers; however, it is possible to include other ingredients adding flavor to preparations without sacrificing the flavor of the final product [20], such as herbs and spices.

Moreover isolated sodium reduction in the preparation is possible if gradually done. One Australian study [21] demonstrated that reductions of up to $30 \%$ do not intervene with the acceptance of preparations. Thus, it would not be possible to completely and in isolated manner reduce the sodium in preparations in order to adequate to the maximum limit of sodium ingestion for the meal in the study at stake. Therefore, we recommend that in the attempt of reducing sodium in preparations to the adequate limit, the use of other ingredients that provide flavor without being enriched in sodium is considered, in order not to compromise the acceptance of preparations and improve the nutritional quality.

We also verified that preparations that most contributed for the dish weight were the accompaniments 1 (29.82\%) and 2 (22.70\%), this result was expected due to the usual intake patterns of the population. Furthermore, this kind of menu (popular) also influences meal composition, as the cost of components is restricted. The protein offer (animal origin) is reduced since it consists of more expensive ingredients. In order to achieve the energy value of the meal, the prioritization of accompaniments is used as a strategy [18].

In this study, these groups were represented by rice and beans that are preparations that are part of the Brazilian food culture and consumed daily. Therefore, the sodium content of these preparations must be carefully controlled in order to reduce its ingestion arising from the size of components portion associated with other components in the menu that are also rich in sodium.

Corroborating to this result, we verified that preparations of accompaniments group 1 also showed greater proportional contribution regarding the sodium amount (32.52\%). In this study, the main representative of this group is rice. Given its color, originally white, other spices may change its color. In order to avoid possible rejection of the preparation, the studied foodservices (91.1\%, Table 2) chose adding salt only and condiments based on onion, garlic and oil in its majority, among other that do not change the color.

Differently from the food group that shows remarkable characteristics of clear color, adding herbs and spices does not negatively interfere with the acceptance of darker preparations or does not influence the acceptance through varied colors, such as preparations of accompaniment group 2 (for example: beans) and garnishes. In this case, the use of herbs and spices is considered a good option for the reduction of salt in preparations without compromising the acceptance because of flavor. Therefore, we can observe in Table 1 that the amount of sodium in accompaniments 2 and garnishe was lower when compared to other hot preparations that compound the menu, showing that, adding spices is possibly easy, promoting greater flavor perception.

The average percentage of sodium obtained for main course (31.99\%) was considered high. This fact possibly occurred due to greater use of chicken $(41.80 \%)$ in the menus (Table 2), since they lack great concentration of extractive substances that gives flavor [22] and requires greater addition of flavor than bovine meat and fish in order to grant pleasant flavor.

Nevertheless, as previously discussed, it is not necessary to use only great amount of salt as spice, as the literature reports, the use of herbs and spices in order to enhance flavor, beyond the use of sauces prepared with concentrated broths can help people responsible for the production of food reduce the sodium offered to clients [20].

By evaluating Table 2, it can be concluded that items that compound appetizers are those that offer lower sodium amount. Raw vegetables represent $86.6 \%$ of the appetizer group and they are served without adding salt, which justifies the low sodium amount in these preparations. The non-encouragement of sodium addition to these preparations by consumers is recommended through the presence of salt cellar and industrialized spices enriched in sodium available on tables and distribution counters, as it is usual in foodservices. Thus, the availability of acid-based sauces (vinegar, citric fruits), herbs and other spices should be chosen, as an option for those that want to spice the appetizers.

Although the garnish group is also predominantly composed of vegetables (35.70\%), it shows lower sodium content for being offered after cooking in water and salt, which promotes the sodium absorption by the vegetables, increasing the concentration of this nutrient. Moreover, other kinds of preparation composing the garnish group, generally, present salt addition as well as other components enriched in sodium upon preparation.

From the evaluated criteria, the sodium distribution was defined based on two parameters: the first one considers the ratio of components weight in the menu regarding the total weight of the meal and the second one considers the sodium distribution of preparations regarding the total amount of sodium in the meal. We also verified the difference between the two proposals (Table 3), which mainly occurs, because the preparations show ingredients that provide various flavor perceptions. However, each foodservice shows particularities that must be considered in the choice of the method for adequacy of the sodium content in meals and that, depending on the main ingredient of each preparation, the use of one or 
other parameter can be defined given the food characteristics.

In Table 3, both parameters show that sodium content may vary according to the amount of each component in the plate, or according to the amount of sodium added upon preparations of meals because some dishes need more sodium addition than others. Therefore, if we consider only the portions on the plate, sodium may be higher used in dishes that do not need that much sodium to improve flavor. However, it is an important factor to be considered since plate's composition in Brazil presents almost $50 \%$ of rice and beans, and their weight influences the amount of sodium in the preparations.

Depending on the choice of dishes on menu planning, nutritionists or chefs may choose both parameters as range values to adequate their sodium offer. It is important to highlight that the sum of sodium of all preparations on a meal should not be higher than recommendations.

Thus, the use of these parameters may help monitoring the sodium addition when different foodservices are preparing the TPFs. This data may direct nutritionists and chefs upon the choice of preparations in the menu, as well as upon the change of preparations so that they better fit the clients' needs.

Considering that the sodium amount offered in lunch for the evaluated clients is similar to the maximum limit of daily sodium ingestion (2300 mg) [9], we can verify the need for reduction of this nutrient in global manner. Thus, new proposed parameters seek after establishing a meal balance in relation to this nutrient, by avoiding damages to the health of the population and upon the acceptance of the preparations.

Beyond the proportional distribution of sodium amount between preparations, the need for reduction in the absolute sodium amount is verified. This goal can be achieved by means of use of differentiated dietary techniques, such as: reduction of the salt addition and products enriched in sodium in the preparations; increase of use of herbs and condiments in order to improve the flavor; change in the cooking method; use of fractionated meat, enabling higher exposure to salt and, consequently, higher absorption, among other. Thus, it is possible to reduce the risks in developing chronic diseases in relation to sodium ingestion.

\section{CONCLUSIONS}

The analysis of the results showed the need for surveillance and monitoring of preparations given the verification of high sodium content. The proposal of sodium distribution in preparations that compose one menu is one way of guiding the foodservices and population on the proper consumption recommended by the WHO. It is also a strategy so that restaurants can better choose the preparations that they will offer and be concerned with standardizing meals and controlling the amount of sodium by means of the development, use and analysis of the TPFs.

We also verified, in this study, that proportionally controlling the sodium percentage is not enough, but also fitting absolute amounts of sodium in each preparation, so that there is not an excess of this nutrient for the population. Furthermore, the sodium distributions for each kind of preparation that compose big meals make the professional practice easy on the technical point of view. This action should promote the adequacy of sodium amount used in meals, by encouraging professionals to seek after new alternatives like the use of spices and herbs and different cooking methods that help to develop the flavor for the optimal acceptance of preparations, without losses in the nutritional characteristics and damages to consumer's health.

Beyond the need for adequacy of food offered by foodservices, the population needs guidelines and nutritional education that cause reflections regarding habits, aiming to reduce the sodium intake. We expect the results of this research to serve for improving the menu planning in restaurants as to fulfill the actual clients' needs in order to prevent diseases.

\section{REFERENCES}

[1] Ribeiro, A.G., Cotta, R.M.M. and Ribeiro, S.M.A. (2012) The promotion of health and integrated prevention of risk factors for cardiovascular diseases. Ciência e Saúde Coletiva, 17, 7-17. http://dx.doi.org/10.1590/S1413-81232012000100002

[2] Campbell, N., Correa-Rotter, R., Neal, B. and Cappuccio, F.P. (2011) New evidence relating to the health impact of reducing salt intake. Nutrition, Metabolism \& Cardiovascular Diseases, 21, 617-619. http://dx.doi.org/10.1016/j.numecd.2011.08.001

[3] Strazzullo, P., D’Elia, L., Kandala, N.B. and Cappuccio, F.P. (2009) Salt intake, stroke, and cardiovascular disease: Meta-analysis of prospective studies. British Medical Journal, 339, 4567. http://dx.doi.org/10.1136/bmj.b4567

[4] Cappuccio, F.P., Kalaitzidis, R., Duneclift, S. and Eastwood, J.B. (2000) Unravelling the links between calcium excretion, salt intake, hypertension, kidney stones and bone metabolism. Journal of Nephrology, 13, 169-77.

[5] He, F.J., Marrero, N.M. and MacGregor, G.A. (2008) Salt intake is related to soft drink consumption in children and adolescents: A link to obesity? Hypertension, 51, 629-634. http://dx.doi.org/10.1161/HYPERTENSIONAHA.107.10 $\underline{0990}$

[6] Morris, M.J., Na, E.S. and Johnson, A.K. (2008) Salt craving: The psychobiology of pathogenic sodium intake. Physiology \& Behavior, 94, 709-721. http://dx.doi.org/10.1016/j.physbeh.2008.04.008

[7] Sarno, F., Claro, R.M., Levy, R.B., Bandoni, D.H., Fer- 
reira, S.R.G. and Monteiro, C.A. (2009) Estimated sodium intake by the Brazilian population, 2002-2003. Revista de Saúde Pública, 43, 219-225. http://dx.doi.org/10.1590/S0034-89102009005000002

[8] BRASIL. Ministério da Saúde (2006) Guia alimentar para a população brasileira.

[9] IOM-Institute of Medicine, Food and Nutrition Board (2004) Dietary reference intake for water, potassium, sodium, chloride and sulfate. National Academies Press, Washington DC.

[10] Spinelli, M.G.N. and Koga, T.T. (2007) Avaliação do consumo de sal em uma unidade de alimentação e nutrição. Revista da Sociedade Brasileira de Alimentação e Nutrição, 32,15-27.

[11] Park, H.R., Jeong, G., Lee, S.L., Kim, J.Y., Kang, S.A., Park, K.Y. and Ryou, H.J. (2009) Workers intake too much salt from dishes of eating out and food service caféterias; Direct chemical analysis of sodium content. Nutrition Research and Practice, 3, 328-333. http://dx.doi.org/10.4162/nrp.2009.3.4.328

[12] Salas, C.K.T.S., Spinelli, M.G.N., Kawashima, L.M. and Ueda, A.M. (2009) Sodium and lipid contents of lunch meals consumed by workers of a company in Suzano, SP, Brazil. Revista de Nutrição, 22, 331-339.

[13] Johnson, C.M., Angell, S.Y., Lederer, A., et al. (2010) Sodium content of lunchtime fast food purchases at major US chains. Archives of Internal Medicine, 170, 732-734. http://dx.doi.org/10.1001/archinternmed.2010.72

[14] Lawrence, G., Salles, C., Septier, C., Busch, J. and ThomasDanguin, T. (2009). Odour-taste interactions: A way to enhance saltiness in low-salt content solutions. Food
Quality and Preference, 20, 241-248. http://dx.doi.org/10.1016/j.foodqual.2008.10.004

[15] Bandoni, D.H. and Jaime, P.C. (2008) The quality of meals in companies participating in the worker's food program in the city of São Paulo, Brazil. Revista de $\mathrm{Nu}$ trição, 21, 177-184.

[16] Akutsu, R.C., Botelho, R.A., Camargo, E.B., Savio, K.E.O. and Araujo, W.C. (2005) The technical cards as quality instrument for good manufacturing process. Revista de Nutrição, 18, 277-279.

[17] Cochran, W.G. (1977) Sampling techniques. 3rd Edition, Wiley, New York.

[18] Domene, S.M.A. (2011) Técnica dietética: Teoria e aplicações. Guanabara Koogan, Rio de Janeiro.

[19] TACO. Tabela Brasileira de Composição de Alimentos (2006) Nepa-Unicamp. 2nd Edition, NEPA-UNICAMP, Campinas.

[20] Carter, B.E., Monsivais, P. and Drewnowski, A. (2011) The sensory optimum of chicken broths supplemented with calcium di-glutamate: A possibility for reducing sodium while maintaining taste. Food Quality and Preference, 22, 699-703. http://dx.doi.org/10.1016/j.foodqual.2011.05.003

[21] Cobcroft, M., Tikellis, K. and Busch, J.L.H.C. (2008) Salt reduction-A technical overview. Food Australia, 60, 8386.

[22] Araujo, W.M.C., Montebello, N.P., Botelho, R.B.A. and Borgo, L.A. (2011) Alquimia dos alimentos. SENAC, Brasilia. 